\title{
A Rise in Percentages of Circulating Lymphocyte Subsets Correlates With Acute Rejection in Liver Transplant Recipients
}

\section{Fei Pan}

Capital Medical University

\section{Shuang Cao}

Capital Medical University

Xian-Liang Li

Capital Medical University

Wen-Li Xu

Capital Medical University

Han Li

Capital Medical University

Ya-nan Jia

Capital Medical University

Qiang He

Capital Medical University

Jiqiao Zhu ( $\nabla$ dr_zhujiqiao@163.com )

Beijing Chaoyang Hospital

\section{Research}

Keywords: Acute rejection, Liver transplantation, Circulating lymphocyte subsets, Follow-up periods

Posted Date: January 6th, 2021

DOI: https://doi.org/10.21203/rs.3.rs-139859/v1

License: (1) (1) This work is licensed under a Creative Commons Attribution 4.0 International License. Read Full License 


\section{Abstract}

Background: Little is known about the shift of circulating lymphocyte subsets following liver transplantation and thus, its relationship with acute rejection.

Methods: Liver transplant recipients were enrolled to assess the effect of primary liver diseases, gender, age, and follow-up periods on the shift of circulating lymphocyte subsets. Moreover, patients with rejection were paired to assess the effect of the shift on rejection.

Results: When compared with patients from the middle-term group (29-180 d) and the long-term group ( $>180 \mathrm{~d}$ ), patients from the short-term group ( $<29 \mathrm{~d}$ ) had the lowest absolute counts of T cell subsets, NK cells and NK T cells, and the lowest percentages of T cell subsets, B cells, NK cells and NK T cells but the highest percentage of DC. However, other factors did not affect circulating lymphocyte subsets. Percentages of T cells, CD $4^{+} \mathrm{T}$ cells, B cells and NK T cells were higher in patients with acute rejection while percentages of $T$ cell subsets and NK cells decreased after anti-rejection treatment. The percentage of NK T cells was identified to be the only independent predictor for acute rejection. The predicted probability was calculated using binary logistic with the area under the curve of 0.89 , which had a sensitivity of $70.6 \%$ and a specificity of $94.1 \%$ at a cut-off value of 0.69 .

Conclusions: Circulating lymphocyte subsets gained a global recovery over the post-transplant period, leading to a sharp rise in percentages of circulating lymphocyte subsets, which was in close relation to the occurrence of acute rejection.

\section{Introduction}

Following liver transplantation, patients are universally plagued by acute rejection, which dominates as a major complication in the early post-transplant period ${ }^{[1]}$. Circulating lymphocyte populations play a key role in the immune response against the allograft. Louis et al identified circulating $T$ helper cells proliferating in the blood of patients undergoing antibody-mediated rejection [2]; Lemerle et al found higher $\mathrm{CD} 8^{+} \mathrm{T}$ cells could increase the risk of acute rejection ${ }^{[3]}$; Schlößer et al reported acute rejection was correlated with an increase of activated B cells and plasmablasts ${ }^{[4]}$; Koenig et al detected that missing self-induced NK cell activation promoted endothelial damage leading to chronic vascular rejection and graft failure ${ }^{[5]}$. However, previous studies mainly focused on a specific cell subpopulation; in the meantime, our understanding of how the circulating lymphocyte subsets as a whole respond to a transplant is lacking. Therefore, we performed the present study to examine dynamic changes of circulating lymphocyte subsets following liver transplantation and thus, their relationship with acute rejection.

\section{Materials And Methods}

\section{Study design}


This is a cross-sectional study to investigate the changes of circulating lymphocyte subsets in liver transplant recipients, who underwent a single liver transplant or were followed up at Beijing Chaoyang Hospital between January 2018 and July 2020. This study consisted of two parts: 1) to evaluate the effect of primary liver diseases, gender, age and follow-up periods on circulating lymphocyte subsets, liver transplant recipients with stable liver function were investigated; 2) to evaluate the relationship between acute rejection and the shift of circulating lymphocyte subsets, another observational group of liver transplant recipients with acute rejection was enrolled and paired. Moreover, the findings would be confirmed by a before-after test after anti-rejection therapy.

There were not any signs of postoperative complications in all cases at the time of sampling except acute rejection. The paired controls with normal liver function did not develop acute rejection if the followup period was $\leq 6$ months; otherwise, they did not have an episode of acute rejection for at least 6 months before sampling. The study was approved by the Institutional Review Board of Beijing Chaoyang Hospital (No.2016-2-19-38) in accordance with the Helsinki declaration of 1975, as revised in 1983. Written informed consent was obtained from all participants.

\section{Immunosuppressive management}

Immunosuppressive therapy consisted of induction with basiliximab (20 mg on day 0 and day 4) and maintenance. As the tacrolimus-based regimen prevailed at our center, patients treated with cyclosporin $A$ were excluded in this study. Methylprednisolone $(500 \mathrm{mg}$ ) was intravenously infused during operation. After surgery, it was given by $240 \mathrm{mg} /$ day, and daily reduced by $40 \mathrm{mg}$ till the 7th postoperative day. Then it was changed to prednisolone $(20 \mathrm{mg} /$ day $)$. Prednisolone was gradually withdrawn within one month afterward.

The diagnosis of acute rejection was made using clinical and laboratory parameters and graft biopsy. The latter was performed whenever necessary for diagnosis and assessed according to the Banff schema ${ }^{[6]}$. Liver transplant recipients with acute rejection were first treated by adding the dosage of tacrolimus. If failed, a new round of steroids was given.

\section{Antibodies and flow cytometric measurement}

The following reagents were all obtained from BD Biosciences: FITC-anti-CD3, CY5.5-anti-CD4, CY5.5-antiCD8, PE-anti-CD19, APC-anti-CD16, PE-anti-CD56, PE-anti-CD4, FITC-anti-Lin1, PerCPCY5.5-anti-CD123, and APC-anti-CD11C. $5 \mathrm{~mL}$ of whole blood for flow cytometric measurement was taken from liver transplant recipients. Peripheral blood mononuclear cells (PBMC) were isolated by ficoll density gradient centrifugation and resuspended in phosphate-buffered saline (PBS). Then, PBMC were stained with antibodies mentioned above at $4^{\circ} \mathrm{C}$ in the dark for $20 \mathrm{~min}$. After that, PBMC were washed once with $2 \mathrm{~mL}$ PBS and resuspended in $400 \mu \mathrm{l}$ PBS for flow cytometry analysis.

Flow cytometry was performed in NovoCyte D2060R (ACEA Biosciences Inc). NovoEXpress software (San Diego, CA, USA) was used for analysis. The lymphocytes evaluated were T $\left(\mathrm{CD} 3^{+}\right), \mathrm{TCD} 4\left(\mathrm{CD} 3^{+} \mathrm{CD} 4^{+}\right)$, TCD $8\left(\mathrm{CD}^{+}{ }^{+} \mathrm{CD} 8^{+}\right), \mathrm{B}\left(\mathrm{CD} 19^{+}\right), \mathrm{NK}\left(\mathrm{CD} 56^{+} \mathrm{CD} 16^{+}\right), \mathrm{NKT}\left(\mathrm{CD} 3^{+} \mathrm{CD} 56^{+} \mathrm{CD} 16^{+}\right)$and DC (lin $1^{-} \mathrm{CD} 11 \mathrm{c}^{+}$and 
lin $\left.1^{-} \mathrm{CD} 123^{+}\right)$. Flow cytometry characterization of circulating lymphocyte subsets was presented in Suppl Fig. 1.

The absolute numbers of lymphocyte subsets were calculated using the percentages obtained in flow cytometry and the lymphocyte counts obtained in routine blood tests on the same day.

\section{Statistical analysis}

Data analyses were carried out by using SPSS 19.0 computer software (IBM Corp., Armonk, NY, USA). All values compared were expressed as mean \pm standard deviation. The Kolmogorov-Smirnov test was used to test for normal distribution of continuous variables. The independent samples t-test was employed for quantitative variables as well as paired samples t-test when appropriate. Significance for the difference between unpaired groups was determined using the Mann-Whitney $U$ test due to non-normal distribution. The Chi-square or Fisher's exact test was used to compare nominal variables. Binary logistic was used for calculating the predicted probability based on the positive parameters. Receiver operating characteristic curve (ROC) analysis and comparison of the area under the curve (AUC) was performed. The cut-off value for positive parameters was further determined by optimal sensitivity and specificity on ROC curve analysis. Multivariable conditional logistic regression was performed to determine independent risk factors for acute rejection. Relative risk was expressed as an odds ratio with a $95 \%$ confidence interval. A p-value $<0.05$ was considered statistically significant. Prism was used for figures.

\section{Results}

\section{Dynamics of circulating lymphocyte subsets changes following liver transplantation}

As circulating lymphocyte subsets have been reported to be affected under physiological and pathological conditions ${ }^{[7-9]}$, we selected liver transplant recipients in the absence of any postoperative complications to minimize the potential impact. A total of 78 liver transplant recipients with stable liver function were enrolled in this study. There were 65 males and 13 females with a median age of 53 years (26-68 years). 22 patients and 56 patients were diagnosed with malignant and benign diseases, respectively. The follow-up period ranged from 4 to 709 days with an average of 137 days after surgery.

First, we wanted to determine whether primary liver diseases would affect the postoperative circulating lymphocyte subsets. Primary liver diseases contained hepatitis-related cirrhosis and hepatitis-related hepatic carcinoma. Female patients were excluded as they all had benign diseases. Since male patients with hepatitis-related hepatic carcinoma were much older ( $58.05 \pm 6.95$ years v.s $50.51 \pm 10.68$ years, $P<$ 0.01 ), male patients with benign diseases of the same age group were selected. Male patients with benign diseases $(n=32)$ and malignant diseases $(n=22)$ had similar age $(55.50 \pm 6.23$ years v.s $58.05 \pm$ 6.95 years, $P>0.05)$ and the follow-up periods $(146.78 \pm 172.89 \mathrm{~d}$ v.s $197.05 \pm 175.11 \mathrm{~d}, \mathrm{P}>0.05)$. There 
was no statistical difference between benign diseases and malignant diseases with respect to the absolute counts and percentages of T, TCD4, TCD8, B, NK, NKT and DC (Suppl Table 1; Fig. 1).

Then, the effect of gender on circulating lymphocyte subsets was evaluated. Male patients with hepatitisrelated cirrhosis and of the same age group as female patients were selected. Male patients $(n=29)$ and female patients $(n=13)$ had similar age $(51.17 \pm 4.85$ years v.s $51.46 \pm 4.58$ years, $P>0.05)$ and the follow-up period ( $153.90 \pm 179.67 \mathrm{~d}$ v.s $82.77 \pm 125.29 \mathrm{~d}, \mathrm{P}>0.05)$. After comparison, there was no statistical difference between male patients and female patients with respect to the absolute counts and percentages of T, TCD4, TCD8, B, NK, NKT and DC (Suppl Table 2; Fig. 2).

Next, we wanted to check whether age played an important role in circulating lymphocyte subsets. Female patients were excluded to minimize potential affection. Subsequently, male patients were divided into the young group ( $<60$ years) and the elderly group ( $\geq 60$ years). Patients from the young group $(49.00 \pm 8.69, n=48)$ and from the elderly group $(64.47 \pm 2.40, n=17)$ had similar percentages of malignant diseases $(13 / 48$ v.s 9/17, $P>0.05)$ and follow-up periods $(150.85 \pm 164.39 \mathrm{~d}$ v.s $141.06 \pm$ $173.43 d, P>0.05)$. There was no statistical difference between young patients and elderly patients with respect to the absolute counts and percentages of T, TCD4, TCD8, B, NK, NKT and DC (Suppl Table 3; Fig. 3).

After that, data from patients with different follow-up periods were analyzed. Female patients were still excluded to minimize potential affection. The follow-up periods were divided into the short-term group (< $29 \mathrm{~d}, \mathrm{n}=22)$, the middle-term group (29-180 d, $n=23$ ) and the long-term group ( $>180 \mathrm{~d}, \mathrm{n}=20$ ). Patients from the three subgroups (short v.s middle v.s long) had similar age $(50.18 \pm 11.65$ years v.s $53.57 \pm$ 10.24 years v.s $55.65 \pm 7.79$ years, $P>0.05)$ and percentages of malignant diseases $(5 / 22$ v.s $8 / 23$ v.s $9 / 20, P>0.05)$. Of note, we found liver transplant recipients gained a global recovery over time. Patients from the short-term group had the lowest absolute counts of T cell subsets $(T, T C D 4$ and TCD8; $P<0.01)$, NK (short v.s middle, $\mathrm{P}<0.05$; short v.s long, $\mathrm{P}<0.01$ ) and NKT (short v.s middle, $\mathrm{P}<0.01$; short v.s long, $\mathrm{P}$ $<0.01)$ and the lowest percentages of T cell subsets (T, TCD4 and TCD8; $P<0.01), B(P<0.05), N K(P<$ 0.05 ) and NKT (short v.s middle, $\mathrm{P}<0.01$; short v.s long, $\mathrm{P}<0.05$ ) but the highest percentage of $\mathrm{DC}$ (short v.s middle, $\mathrm{P}<0.05$; short v.s long, $\mathrm{P}<0.01$ ). The rest results were similar among the subgroups (Suppl Table 4; Fig. 4).

\section{The Shift of circulating lymphocyte subsets during acute rejection and after anti-rejection therapy}

As most acute rejections reported in liver transplant recipients occur within the first year, especially the first six months [10-12], we wanted to know whether a sharp increase in the absolute counts and percentages of lymphocyte subsets was in close relation to acute rejection. Then, a total of 17 patients who experienced acute rejection episodes were enrolled. There were 15 males and 2 females with a median age of 47 years (25-69 years). 6 patients and 11 patients were diagnosed with malignant and benign diseases, respectively. The occurrence time of acute rejection ranged from 22 to 107 days with an 
average of 56 days after surgery. To analyze the changes of lymphocyte subsets patients with rejection were then matched by gender, age ( \pm 3 years), primary liver diseases for transplantation (malignant or benign), and follow-up periods ( $\pm 5 \mathrm{~d}$ ). Data from patients with acute rejection and paired controls were collected.

We found four patients had acute rejection within $28 d$ and 13 patients between $29-180 \mathrm{~d}$ (Fig. 5A), which was in accordance with the reported studies. Notably, the trough levels of tacrolimus were similar between the two groups indicating that the patients received similar immunosuppressive therapy (Fig. 5B). After comparison, we found that percentages of T, TCD4, B and NKT were higher in patients with acute rejection but there was no statistical difference concerning the absolute counts of any circulating lymphocyte subsets (Suppl Table 5, Fig. 6). Next we assessed the ability of percentages of T, TCD4, B and NKT to identify patients at risk for acute rejection. Multivariate Cox analysis showed the percentage of NKT was the strong predictor of acute rejection (Table 1). The area under the curve (AUC) of percentages of TCD4, B and NKT were $0.76,0.73$ and 0.77 on receiver operating characteristic curve analysis, respectively. The predicted probability was calculated using binary logistic that combined percentages of TCD4, B and NKT (AUC 0.89; Fig. 5C). At a cut-off value of 0.69 , this new marker had a sensitivity of $70.6 \%$ and a specificity of $94.1 \%$.

Table 1

Multivariate Cox analysis

\begin{tabular}{|lll|}
\hline Percentages & HR $(95 \%$ Cl) & P value \\
\hline TCD4 & $0.981-1.214$ & 0.109 \\
\hline B & $0.962-1.749$ & 0.088 \\
\hline NKT & $1.059-2.971$ & 0.029 \\
\hline
\end{tabular}

TCD4, $\mathrm{CD}^{+}{ }^{+} \mathrm{CD} 4^{+} \mathrm{T}$ cells; $\mathrm{B}, \mathrm{CD} 19^{+} \mathrm{B}$ cells; $\mathrm{NKT}, \mathrm{CD}^{+} \mathrm{CD} 56^{+} \mathrm{CD} 16^{+}$Natural killer T cells; $\mathrm{Cl}$, confidence interval; $\mathrm{HR}$, hazard ratio.

Finally, in an attempt to confirm the role that percentages of circulating lymphocyte subsets played in acute rejection, these patients were sampled for a second time following anti-rejection therapy. All were first treated by adding the dosage of tacrolimus. Subsequently, 9 patients were treated with steroids due to uncontrollable rejection. All cases recovered gradually and finally had a normal liver function. The periods between before and after sampling ranged from 8 to $26 \mathrm{~d}$. Data of before-after sampling were collected and compared. Notably, the results showed that percentages of T, TCD4, TCD8 and NK were lower after the treatment while the absolute counts of lymphocyte subsets remained similar between the groups (Suppl Table 6; Fig. 7).

\section{Discussion}

In this study, we found that circulating lymphocyte subsets from liver transplant recipients gained a global recovery over the post-transplant period, leading to a sharp rise in percentages of circulating 
lymphocyte subsets, which was in close relation to the occurrence of acute rejection.

Many studies described the changes of a specific cell subpopulation in various diseases ${ }^{[13-15]}$. However, little is known about the shift of circulating lymphocyte subsets following liver transplantation. We found that primary liver diseases, gender and age failed to impact on the circulating lymphocyte subsets, which are not in agreement with others who described earlier. Grassberger et al found the number of circulating T cells was higher in liver cancer patients with longer overall survival ${ }^{[16]}$. Freitas et al found patients with benign renal diseases had lower absolute counts of $T$ cell subsets and $B$ cells when compared with healthy controls ${ }^{[17]}$. Nevertheless, none of them compared malignant diseases with benign diseases. Ravindran et al reported circulating NK cells in female patients were lower than in male patients but they compared typical depression with atypical depression, which might be different from our results ${ }^{[18]}$. Freitas et al reported aging presented an effect on decreasing absolute numbers of B and T-lymphocytes in patients as well as in healthy controls because their subjects were divided by $\leq 45$ and $>60$ years in contrast to our $<60$ and $\geq 60$ years ${ }^{[17]}$. Typically, most lymphocyte subsets clonally expand and differentiate at different rates over the follow-up period as we found in this study. Surprisingly, the percentages of B cells and DC decreased over time. Similarly, it was also detected that circulating pDC were reduced in renal transplant recipients although we collected data of $\mathrm{pDC}$ and $\mathrm{mDC}$; both $\mathrm{pDC}$ and $\mathrm{mDC}$ were functionally impaired which might affect their proliferation ${ }^{[19]}$. Moreover, decreased total B-cell counts in renal transplant recipients have already been reported ${ }^{[20]}$. Additionally, the rapid growth of other cell subsets might make their percentages relatively lower.

Acute rejection is a combined response of cellular immunity and humoral immunity in combination with the innate immune system ${ }^{[21-23]}$. Therefore, the circulating lymphocyte subsets should be regarded as a whole as each cell subpopulation correlates with the other. With the recovery of circulating lymphocyte subsets over time, the incidence of acute rejection is higher within 6 months in our study. Tacrolimus levels were comparable between patients with and without acute rejection so they received similar immunosuppression in addition to similar counts of lymphocyte subsets. Of note, percentages of circulating lymphocyte subsets were much higher in the rejection group including T, TCD4, B and NKT. $\mathrm{CD} 4^{+} \mathrm{T}$ cells are critical to participate in acute rejection, whose development is promoted by antigenpresenting cells. Subsets of $\mathrm{CD} 4^{+} \mathrm{T}$ cells were identified based on the production of cytokines, mediating cell-mediated immunity ${ }^{[24]}$ and humoral immunity ${ }^{[25]}$. In heart transplantation, patients with acute rejection had a higher proportion of circulating $C D 4^{+} T$ cells ${ }^{[26]}$. van Besouw et al reported $C D 4^{+} T$ cells are associated with an increased risk of rejection via secretion of cytokines ${ }^{[27]}$. B cells are found to be involved in antibody-mediated rejection via secreting cytokines to enhance or inhibit immune responses. Circulating B cells decreased in patients without signs of rejection and were significantly elevated in patients with renal allograft rejection ${ }^{[4]}$. San Segundo et al even found an increased frequency of circulating B cells before transplantation could identify patients at risk of acute rejection ${ }^{[28]}$. In this study we identified NKT cells to be the only independent predictor. NKT cells are a kind of innate immune cells, which can release pro- and anti-inflammatory cytokines upon TCR engagement and exhibit powerful 
regulatory properties ${ }^{[29]}$. NKT cells are believed to be responsible for tolerance induction ${ }^{[30]}$, thus, the increased frequency of NKT cells in our study may indicate an attempt to be involved in the local control of acute rejection as reported in renal and heart transplant recipients ${ }^{[31,32]}$.

The role of circulating lymphocyte subset percentages was further validated in an independent beforeafter test because percentages of T, TCD4, TCD8 and NK were significantly lower after anti-rejection therapy while the absolute cell counts remained the same. After the administration of prednisone or tacrolimus, there was a profound lymphocytopenia, a selective decrease in T cells and NK cells ${ }^{[33-35]}$. Nevertheless, there was no relation between prednisone or tacrolimus dose and tacrolimus trough level on $B$ cells and DC as mycophenolate mofetil had an impact on suppression of B-cell functions ${ }^{[36,37]}$.

\section{Abbreviations}

PBMC, peripheral blood mononuclear cells; PBS, phosphate-buffered saline; T, CD3 ${ }^{+} T$ cells; TCD4, $\mathrm{CD}^{+} \mathrm{CD} 4^{+} \mathrm{T}$ cells; $\mathrm{TCD} 8, \mathrm{CD} 3^{+} \mathrm{CD} 8^{+} \mathrm{T}$ cells; $\mathrm{B}, \mathrm{CD} 19^{+} \mathrm{B}$ cells; NK, $\mathrm{CD} 56^{+} \mathrm{CD} 16^{+}$Natural killer cells; NKT, $\mathrm{CD}^{+}{ }^{+} \mathrm{CD} 56^{+} \mathrm{CD} 16^{+}$Natural killer T cells; DC, lin1 ${ }^{-} \mathrm{CD} 11 \mathrm{c}^{+}$and $\operatorname{lin} 1{ }^{-} \mathrm{CD} 123^{+}$Dendritic cells; AUC, area under the curve

\section{Declarations}

Ethics approval and consent to participate

The study was approved by the Institutional Review Board of Beijing Chaoyang Hospital (No.2016-2-1938 ) in accordance with the Helsinki declaration of 1975, as revised in 1983. Written informed consent was obtained from all participants.

\section{Consent for publication}

Not applicable

Competing interest

Not applicable

\section{Funding}

This work is supported by Open Project of Beijing Key Laboratory of Tolerance Induction and Organ Protection in Transplantation (2017YZNS01) and National Natural Science Foundation of China (81571554 and 81601392).

Authors' contributions 
ZJ and HQ contributed conception and design of the study; PF, CS and LX organized the database; JY, XW and LH performed the statistical analysis; PF, CS and LX wrote the first draft of the manuscript; the rest of the authors wrote sections of the manuscript. All authors contributed to manuscript revision, read and approved the submitted version.

\section{Acknowledgments}

Not applicable

Availability of data and materials

All data generated or analysed during this study are included in this published article

\section{References}

1. Adams DH, Sanchez-Fueyo A, Samuel D. From immunosuppression to tolerance. J Hepatol 2015, 62(1 Suppl): S170-185.

2. Louis K, Macedo C, Bailly E, Lau L, Ramaswami B, Marrari M, Landsittel D, Chang A, Chandran U, Fadakar P, Yamada M, Chalasani G, Randhawa P, Zeevi A, Singh H, Lefaucheur C, Metes D. Coordinated Circulating T Follicular Helper and Activated B Cell Responses Underlie the Onset of Antibody-Mediated Rejection in Kidney Transplantation. J Am Soc Nephrol 2020, 31(10): 2457-2474.

3. Lemerle M, Garnier AS, Planchais M, Brilland B, Subra JF, Blanchet O, Blanchard S, Croue A, Duveau A, Augusto JF. CD45RC Expression of Circulating CD8(+) T Cells Predicts Acute Allograft Rejection: A Cohort Study of 128 Kidney Transplant Patients. J Clin Med 2019, 8(8).

4. Schlosser HA, Thelen M, Dieplinger G, von Bergwelt-Baildon A, Garcia-Marquez M, Reuter S, Shimabukuro-Vornhagen A, Wennhold K, Haustein N, Buchner D, Heiermann N, Kleinert R, Wahba R, Ditt V, Kurschat C, Cingoz T, Becker J, Stippel DL, von Bergwelt-Baildon M. Prospective Analyses of Circulating B Cell Subsets in ABO-Compatible and ABO-Incompatible Kidney Transplant Recipients. Am J Transplant 2017, 17(2): 542-550.

5. Koenig A, Chen CC, Marcais A, Barba T, Mathias V, Sicard A, Rabeyrin M, Racape M, Duong-VanHuyen JP, Bruneval P, Loupy A, Dussurgey S, Ducreux S, Meas-Yedid V, Olivo-Marin JC, Paidassi H, Guillemain R, Taupin JL, Callemeyn J, Morelon E, Nicoletti A, Charreau B, Dubois V, Naesens M, Walzer T, Defrance T, Thaunat O. Missing self triggers NK cell-mediated chronic vascular rejection of solid organ transplants. Nat Commun 2019, 10(1): 5350.

6. Banff schema for grading liver allograft rejection: an international consensus document. Hepatology 1997, 25(3): 658-663.

7. Peake JM, Neubauer 0 , Walsh NP, Simpson RJ. Recovery of the immune system after exercise. J Appl Physiol (1985) 2017, 122(5): 1077-1087.

8. Mehta D, Miller C, Arnold DL, Bame E, Bar-Or A, Gold R, Hanna J, Kappos L, Liu S, Matta A, Phillips JT, Robertson D, von Hehn CA, Campbell J, Spach K, Yang L, Fox RJ. Effect of dimethyl fumarate on 
lymphocytes in RRMS: Implications for clinical practice. Neurology 2019, 92(15): e1724-e1738.

9. Venkatesulu BP, Mallick S, Lin SH, Krishnan S. A systematic review of the influence of radiationinduced lymphopenia on survival outcomes in solid tumors. Crit Rev Oncol Hematol 2018, 123: 4251.

10. Volpin R, Angeli P, Galioto A, Fasolato S, Neri D, Barbazza F, Merenda R, Del Piccolo F, Strazzabosco M, Casagrande F, Feltracco P, Sticca A, Merkel C, Gerunda G, Gatta A. Comparison between two highdose methylprednisolone schedules in the treatment of acute hepatic cellular rejection in liver transplant recipients: a controlled clinical trial. Liver Transpl 2002, 8(6): 527-534.

11. Saliba F, Duvoux C, Gugenheim J, Kamar N, Dharancy S, Salame E, Neau-Cransac M, Durand F, Houssel-Debry P, Vanlemmens C, Pageaux G, Hardwigsen J, Eyraud D, Calmus Y, Di Giambattista F, Dumortier J, Conti F. Efficacy and Safety of Everolimus and Mycophenolic Acid With Early Tacrolimus Withdrawal After Liver Transplantation: A Multicenter Randomized Trial. Am J Transplant 2017, 17(7): 1843-1852.

12. Jucaud V, Shaked A, DesMarais M, Sayre P, Feng S, Levitsky J, Everly MJ. Prevalence and Impact of De Novo Donor-Specific Antibodies During a Multicenter Immunosuppression Withdrawal Trial in Adult Liver Transplant Recipients. Hepatology 2019, 69(3): 1273-1286.

13. Segal NH, He AR, Doi T, Levy R, Bhatia S, Pishvaian MJ, Cesari R, Chen Y, Davis CB, Huang B, Thall AD, Gopal AK. Phase I Study of Single-Agent Utomilumab (PF-05082566), a 4-1BB/CD137 Agonist, in Patients with Advanced Cancer. Clin Cancer Res 2018, 24(8): 1816-1823.

14. Rapaport MH. Circulating lymphocyte phenotypic surface markers in anxiety disorder patients and normal volunteers. Biol Psychiatry 1998, 43(6): 458-463.

15. Fu Y, Hao J, Zhang N, Ren L, Sun N, Li YJ, Yan Y, Huang D, Yu C, Shi FD. Fingolimod for the treatment of intracerebral hemorrhage: a 2-arm proof-of-concept study. JAMA Neurol 2014, 71(9): 1092-1101.

16. Grassberger C, Hong TS, Hato T, Yeap BY, Wo JY, Tracy M, Bortfeld T, Wolfgang JA, Eyler CE, Goyal L, Clark JW, Crane CH, Koay EJ, Cobbold M, DeLaney TF, Jain RK, Zhu AX, Duda DG. Differential Association Between Circulating Lymphocyte Populations With Outcome After Radiation Therapy in Subtypes of Liver Cancer. Int J Radiat Oncol Biol Phys 2018, 101(5): 1222-1225.

17. Freitas GRR, da Luz Fernandes M, Agena F, Jaluul O, Silva SC, Lemos FBC, Coelho V, Elias DN, Galante NZ. Aging and End Stage Renal Disease Cause A Decrease in Absolute Circulating Lymphocyte Counts with A Shift to A Memory Profile and Diverge in Treg Population. Aging Dis 2019, 10(1): 49-61.

18. Ravindran AV, Griffiths J, Merali Z, Anisman H. Circulating lymphocyte subsets in major depression and dysthymia with typical or atypical features. Psychosom Med 1998, 60(3): 283-289.

19. Lim WH, Kireta S, Thomson AW, Russ GR, Coates PT. Renal transplantation reverses functional deficiencies in circulating dendritic cell subsets in chronic renal failure patients. Transplantation 2006, 81(2): 160-168.

20. van de Berg PJ, Hoevenaars EC, Yong SL, van Donselaar-van der Pant KA, van Tellingen A, Florquin S, van Lier RA, Bemelman FJ, ten Berge IJ. Circulating lymphocyte subsets in different clinical 
situations after renal transplantation. Immunology 2012, 136(2): 198-207.

21. Fahrner R, Dondorf F, Ardelt M, Settmacher U, Rauchfuss F. Role of NK, NKT cells and macrophages in liver transplantation. World J Gastroenterol 2016, 22(27): 6135-6144.

22. Montgomery RA, Loupy A, Segev DL. Antibody-mediated rejection: New approaches in prevention and management. Am J Transplant 2018, 18 Suppl 3: 3-17.

23. Sanchez-Fueyo A, Strom TB. Immunologic basis of graft rejection and tolerance following transplantation of liver or other solid organs. Gastroenterology 2011, 140(1): 51-64.

24. Cher DJ, Mosmann TR. Two types of murine helper T cell clone. II. Delayed-type hypersensitivity is mediated by TH1 clones. J Immunol 1987, 138(11): 3688-3694.

25. Smith KM, Pottage L, Thomas ER, Leishman AJ, Doig TN, Xu D, Liew FY, Garside P. Th1 and Th2 CD4+ $T$ cells provide help for $B$ cell clonal expansion and antibody synthesis in a similar manner in vivo. J Immunol 2000, 165(6): 3136-3144.

26. Sannier A, Stroumza N, Caligiuri G, Le Borgne-Moynier M, Andreata F, Senemaud J, Louedec L, Even G, Gaston AT, Deschildre C, Couvelard A, Ou P, Cheynier R, Nataf P, Dorent R, Nicoletti A. Thymic function is a major determinant of onset of antibody-mediated rejection in heart transplantation. Am J Transplant 2018, 18(4): 964-971.

27. van Besouw NM, Yan L, de Kuiper R, Klepper M, Reijerkerk D, Dieterich M, Roelen DL, Claas FHJ, Clahsen-van Groningen MC, Hesselink DA, Baan CC. The Number of Donor-Specific IL-21 Producing Cells Before and After Transplantation Predicts Kidney Graft Rejection. Front Immunol 2019, 10: 748.

28. San Segundo D, Rodrigo E, Kislikova M, Ruiz JC, Fernandez-Fresnedo G, Asensio E, Arias M, LopezHoyos M. Frequencies of circulating B-cell subpopulations before kidney transplantation identify patients at risk of acute rejection. Transplant Proc 2015, 47(1): 54-56.

29. Gerth E, Mattner J. The Role of Adaptor Proteins in the Biology of Natural Killer T (NKT) Cells. Front Immunol 2019, 10: 1449.

30. Margalit M, Ilan Y. Induction of immune tolerance: a role for Natural killer T lymphocytes? Liver Int 2005, 25(3): 501-504.

31. Zhu J, Zeng Y, Dolff S, Bienholz A, Lindemann M, Brinkhoff A, Schedlowski M, Xu S, Sun M, Guberina $\mathrm{H}$, Kirchhof J, Kribben A, Witzke O, Wilde B. Granzyme B producing B-cells in renal transplant patients. Clin Immunol 2017, 184: 48-53.

32. Chen M, Mohtize M, Mattei MF, Villemot JP, Kohler C, Faure GC, Bene MC, de Carvalho Bittencourt M. Reduced levels of both circulating CD4+ CD25+ CD127(low/neg) and CD4+ CD8(neg) invariant natural killer regulatory T cells in stable heart transplant recipients. Clin Exp Immunol 2011, 163(1): 104-112.

33. Zweiman B, Atkins PC, Bedard PM, Flaschen SL, Lisak RP. Corticosteroid effects on circulating lymphocyte subset levels in normal humans. J Clin Immunol 1984, 4(2): 151-155.

34. Vacher-Coponat H, Brunet C, Moal V, Loundou A, Bonnet E, Lyonnet L, Ravet S, Sampol-Manos E, Sampol J, Berland Y, George FD, Paul P. Tacrolimus/mycophenolate mofetil improved natural killer 
lymphocyte reconstitution one year after kidney transplant by reference to cyclosporine/azathioprine. Transplantation 2006, 82(4): 558-566.

35. Gerrits $\mathrm{JH}$, van de Wetering J, Weimar W, van Besouw NM. T-cell reactivity during tapering of immunosuppression to low-dose monotherapy prednisolone in HLA-identical living-related renal transplant recipients. Transplantation 2009, 87(6): 907-914.

36. Tokita D, Mazariegos GV, Zahorchak AF, Chien N, Abe M, Raimondi G, Thomson AW. High PDL1/CD86 ratio on plasmacytoid dendritic cells correlates with elevated T-regulatory cells in liver transplant tolerance. Transplantation 2008, 85(3): 369-377.

37. Weimer R, Deisz S, Dietrich H, Renner F, Bodeker RH, Daniel V, Kamali-Ernst S, Ernst W, Padberg W, Opelz G. Impact of maintenance immunosuppressive regimens-balance between graft protective suppression of immune functions and a near physiological immune response. Transpl Int 2011, 24(6): 596-609.

\section{Figures}

A

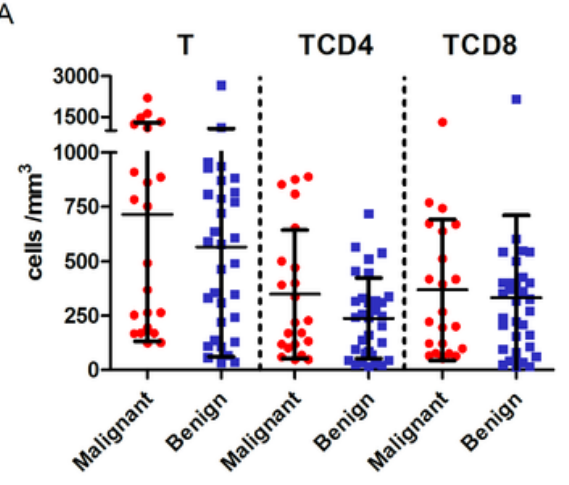

D

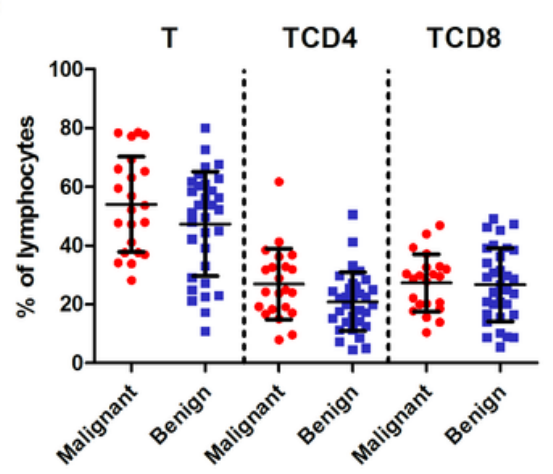

B

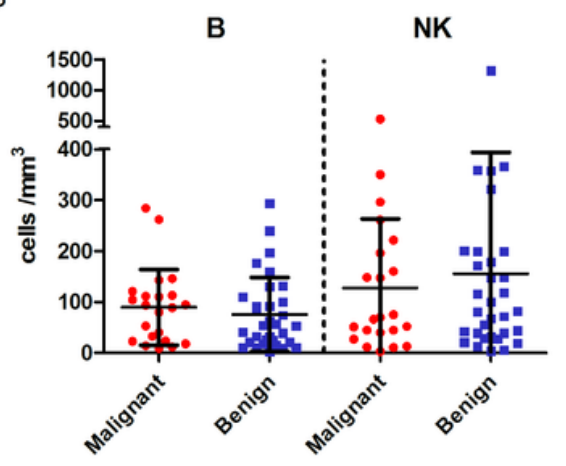

E

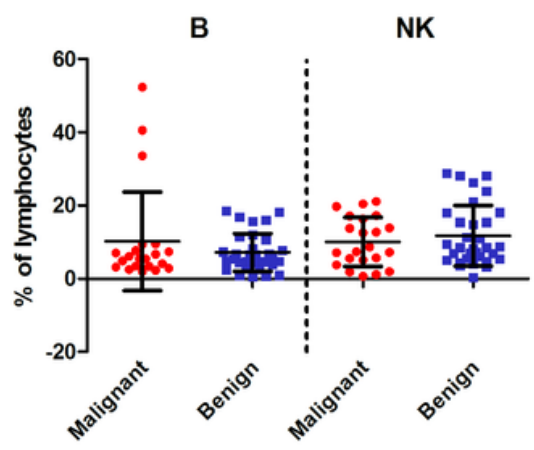

C
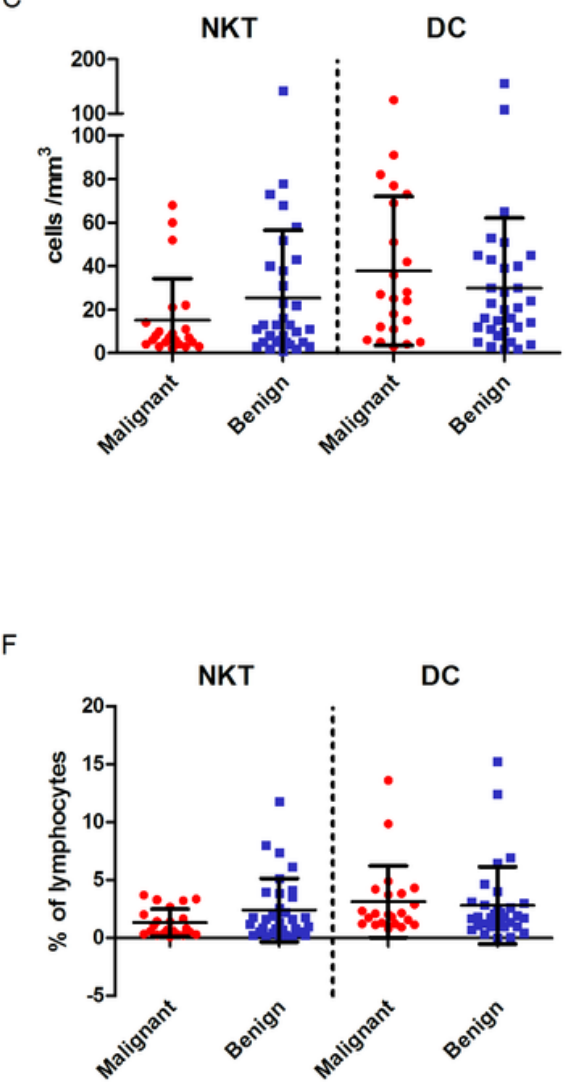

Figure 1

Primary liver diseases failed to have an impact on absolute numbers and percentages of lymphocyte subsets. Comparison of absolute numbers (A-C) and percentages (D-F) of T, TCD4, TCD8, B, NK, NKT, and 
DC between liver transplant recipients with malignant $(n=22)$ and benign $(n=32)$ diseases. Bars represent mean and standard deviation. T, CD3+T cells; TCD4, CD3+CD4+T cells; TCD8, CD3+CD8+T cells; B, CD19+B cells; NK, CD56+CD16+Natural killer cells; NKT, CD3+CD56+CD16+Natural killer T cells; DC, lin1CD11c+ and lin1-CD123+Dendritic cells.

A

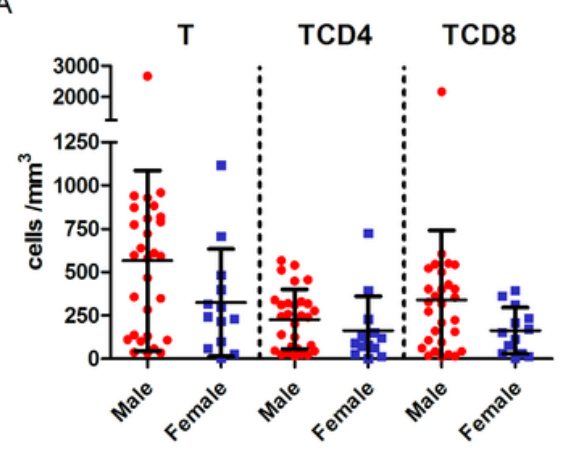

D

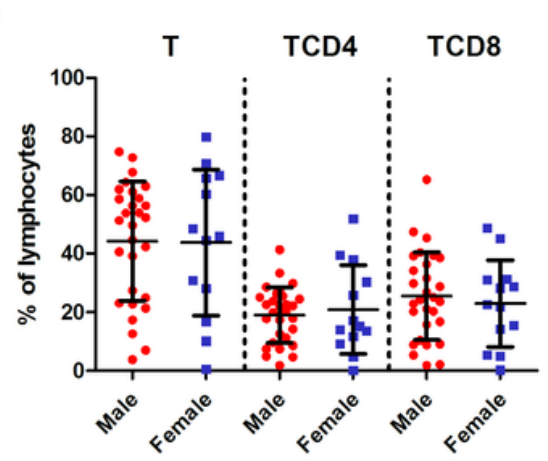

B

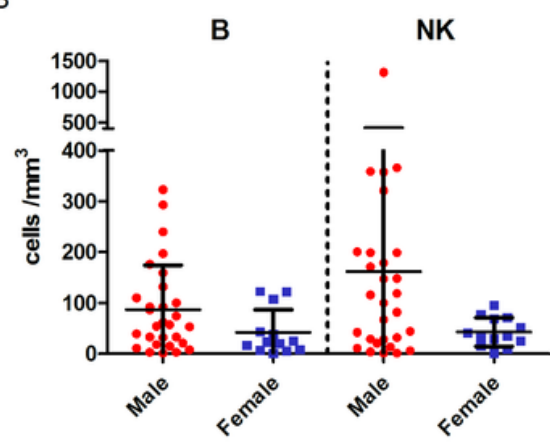

$\mathrm{E}$

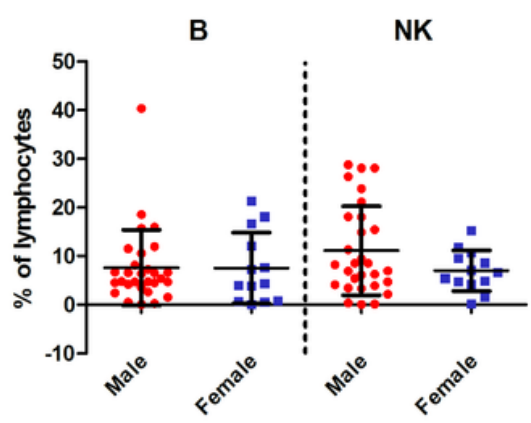

C

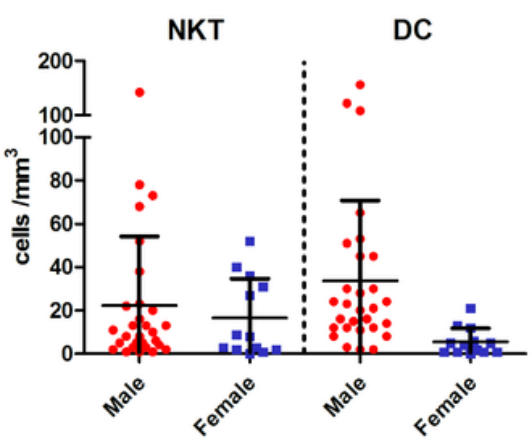

$\mathrm{F}$

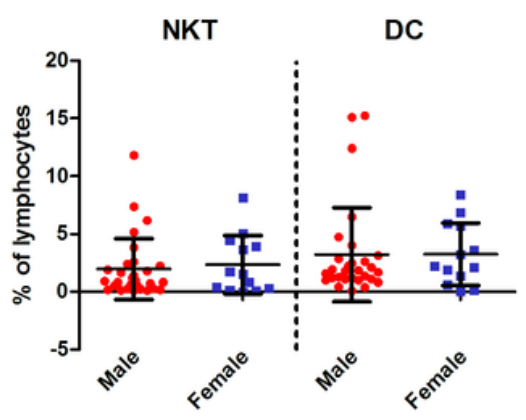

\section{Figure 2}

Gender failed to have an impact on absolute numbers and percentages of lymphocyte subsets. Comparison of absolute numbers (A-C) and percentages (D-F) of T, TCD4, TCD8, B, NK, NKT, and DC between male patients $(n=29)$ and female patients $(n=13)$. Bars represent mean and standard deviation. T, CD3+T cells; TCD4, CD3+CD4+T cells; TCD8, CD3+CD8+T cells; B, CD19+B cells; NK, CD56+CD16+Natural killer cells; NKT, CD3+CD56+CD16+Natural killer T cells; DC, lin1-CD11c+ and lin1CD123+Dendritic cells. 
A
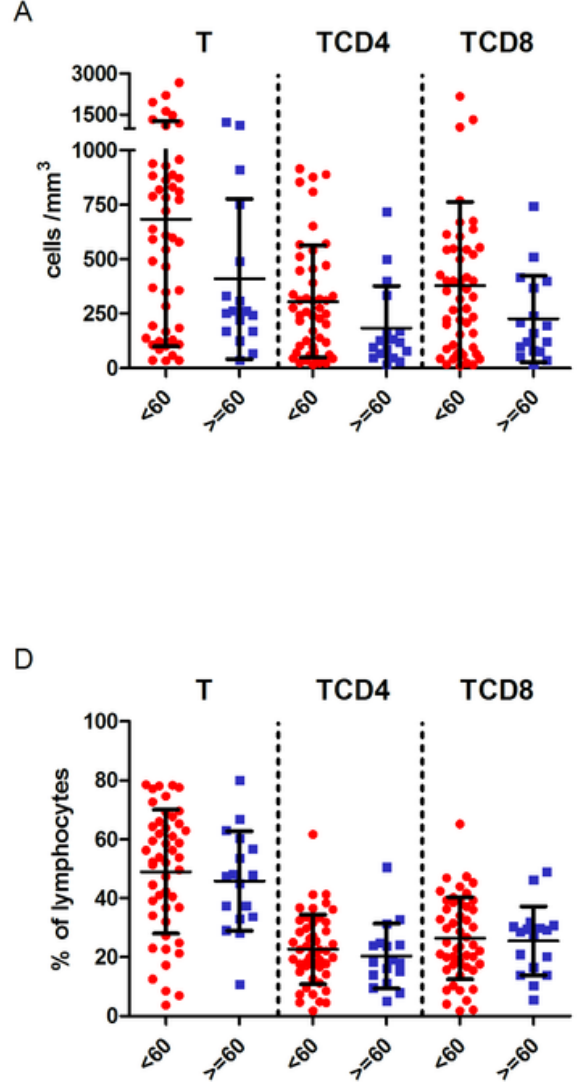

B

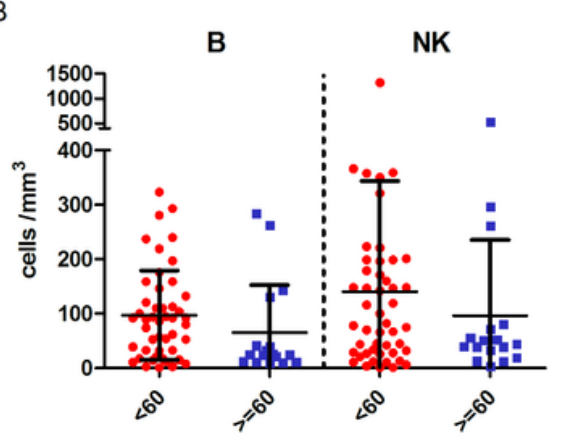

$\mathrm{E}$

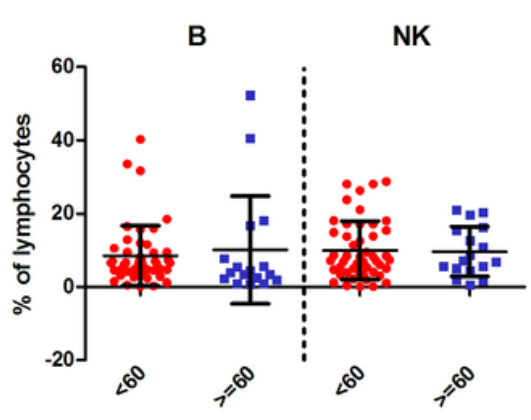

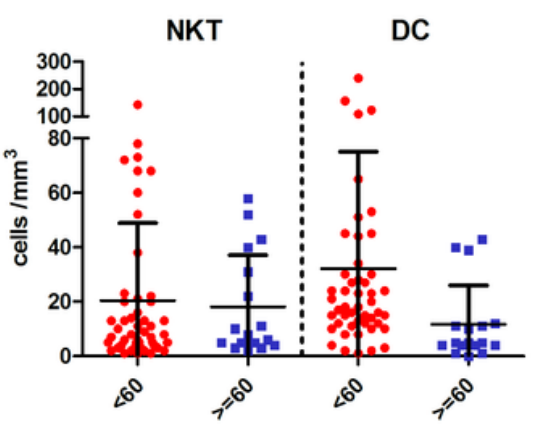

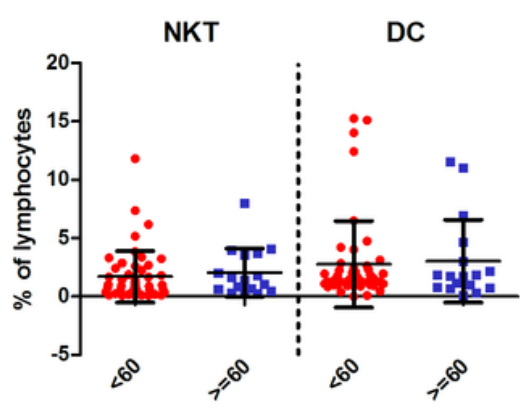

Figure 3

Age failed to have an impact on absolute numbers and percentages of lymphocyte subsets. Comparison of absolute numbers (A-C) and percentages (D-F) of T, TCD4, TCD8, B, NK, NKT, and DC between liver transplant recipients $<60$ years $(n=48)$ and $\geq 60$ years $(n=17)$. Bars represent mean and standard deviation. T, CD3+T cells; TCD4, CD3+CD4+T cells; TCD8, CD3+CD8+T cells; B, CD19+B cells; NK, CD56+CD16+Natural killer cells; NKT, CD3+CD56+CD16+Natural killer T cells; DC, lin1-CD11C+ and lin1CD123+Dendritic cells 
A

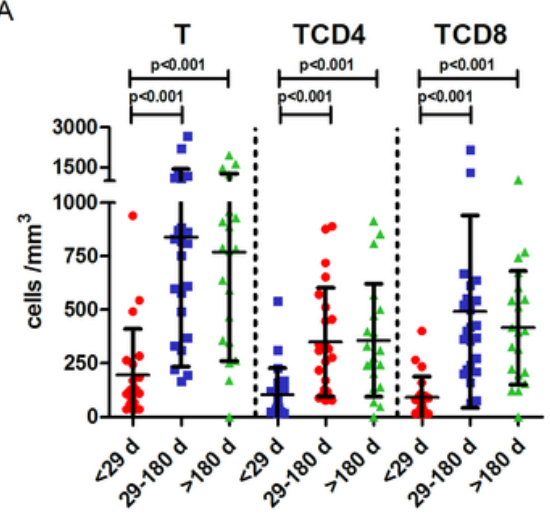

D

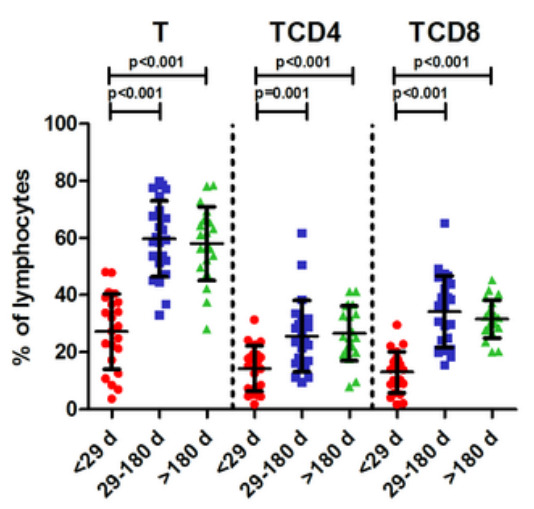

B

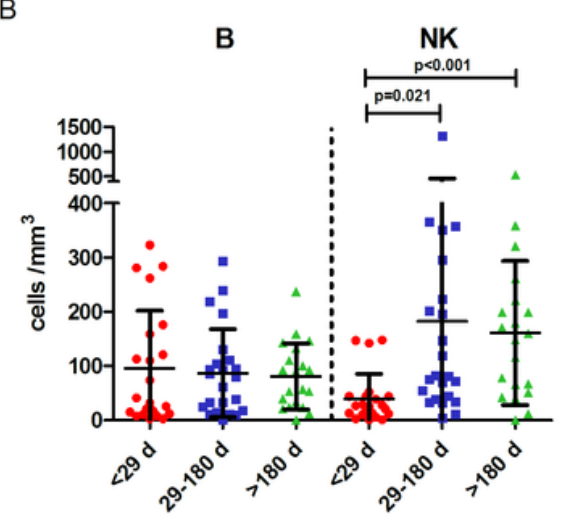

E

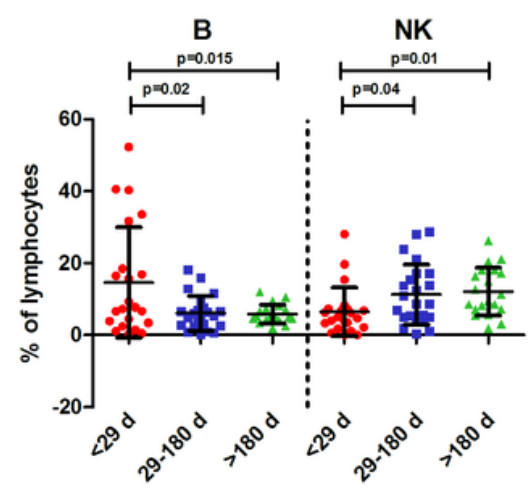

C

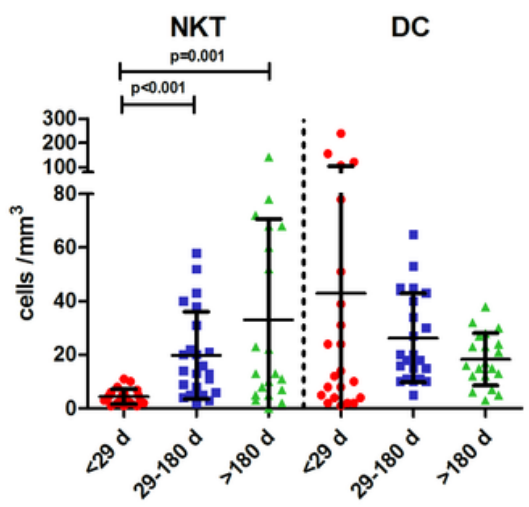

$\mathrm{F}$

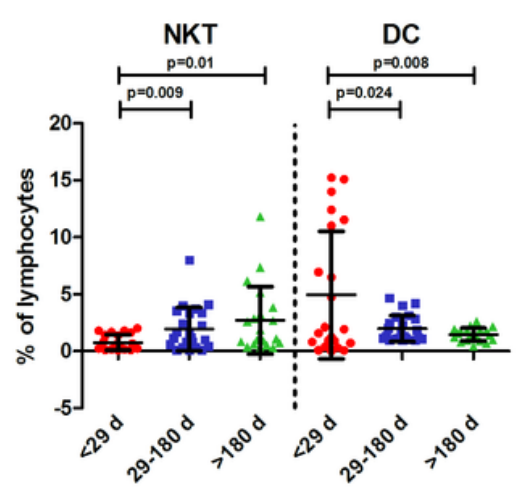

\section{Figure 4}

The shift of absolute numbers and percentages of lymphocyte subsets over the follow-up periods Comparison of absolute numbers (A-C) and percentages (D-F) of T, TCD4, TCD8, B, NK, NKT, and DC between liver transplant recipients with a follow-up period $<29 d(n=22), 29-180 d(n=23)$ and $>180 d$ $(n=20)$. Bars represent mean and standard deviation. T, CD3+T cells; TCD4, CD3+CD4+T cells; TCD8, CD3+CD8+T cells; B, CD19+B cells; NK, CD56+CD16+Natural killer cells; NKT, CD3+CD56+CD16+Natural killer T cells; DC, lin1-CD11C+ and lin1-CD123+Dendritic cells 
A

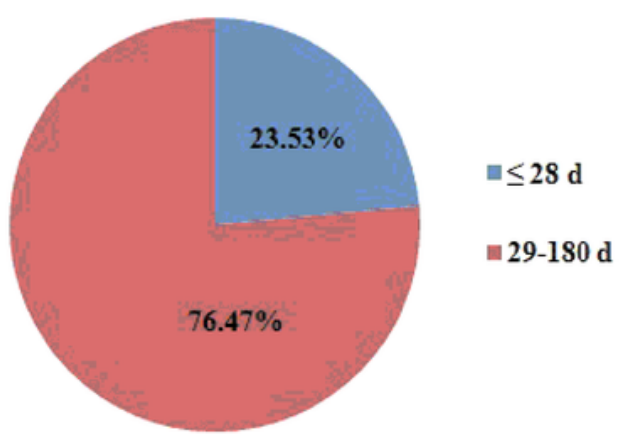

B

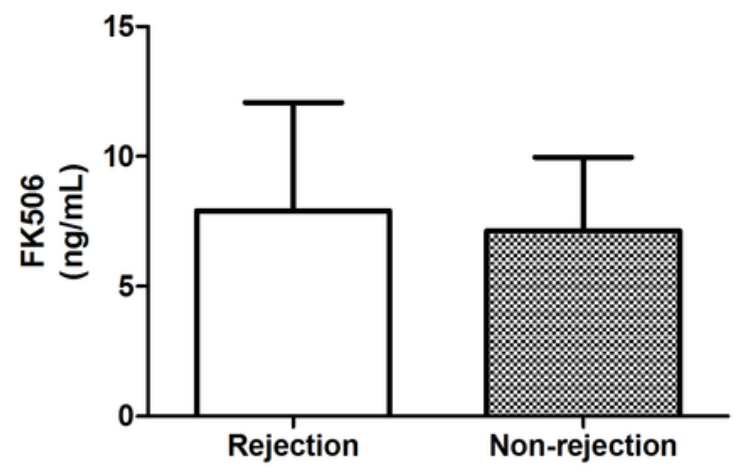

C

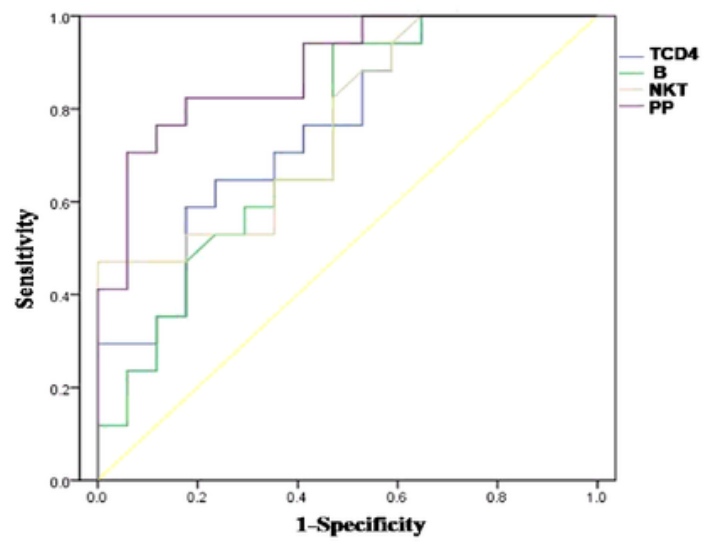

$$
\begin{array}{|l|l|}
\cline { 2 - 2 } \multicolumn{1}{c|}{} & \text { AUC } \\
\hline \text { TCD4 } & 0.76 \\
\text { B } & 0.73 \\
\text { NKT } & 0.77 \\
\text { PP } & 0.89 \\
\hline
\end{array}
$$

\section{Figure 5}

Recovery of percentages of lymphocyte subsets might promote the occurrence of acute rejection. Incidence of acute rejection at different follow-up periods (A); Trough levels of tacrolimus compared between patients with rejection and without rejection (B); Receiver operating characteristic curve analysis for acute rejection (C). TCD4, CD3+CD4+T cells; B, CD19+B cells; NKT, CD3+CD56+CD16+Natural killer T cells; PP, predicted probability; AUC, area under the curve 
A

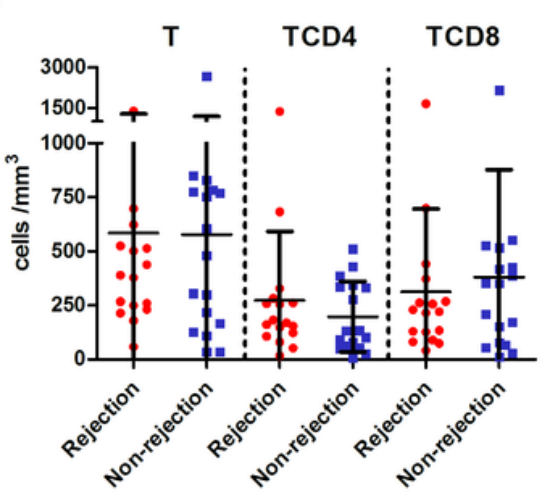

D

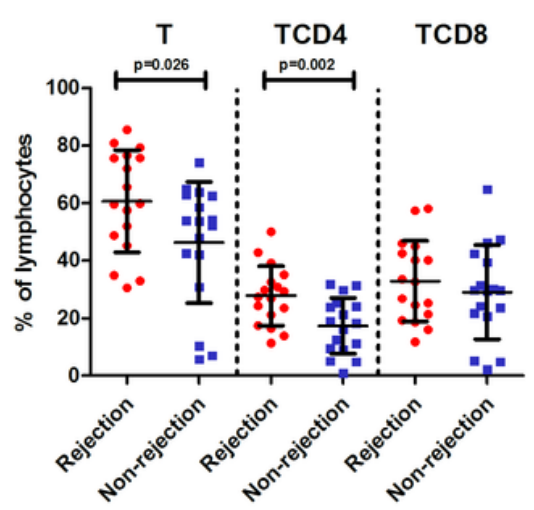

B

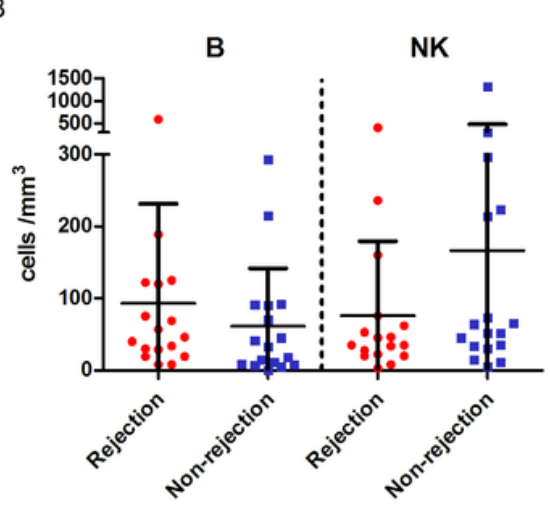

$\mathrm{E}$

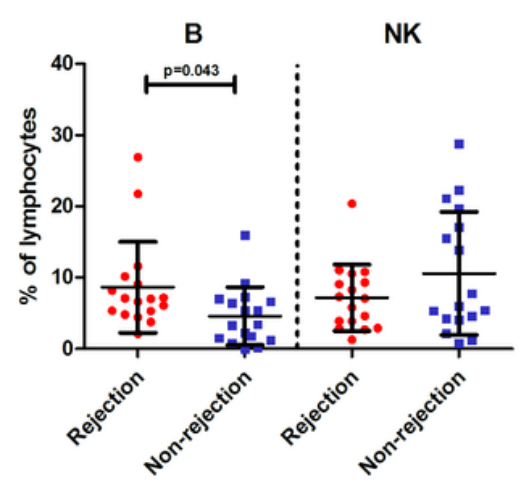

C

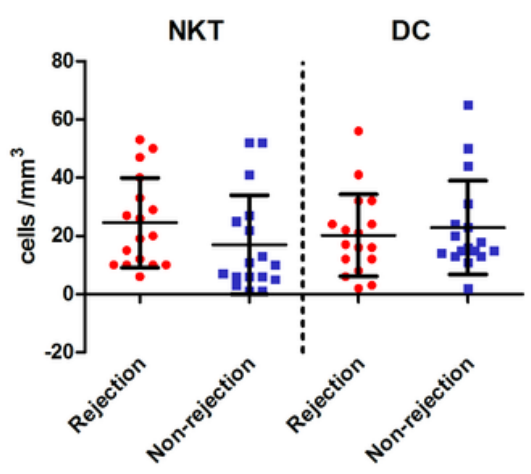

$\mathrm{F}$

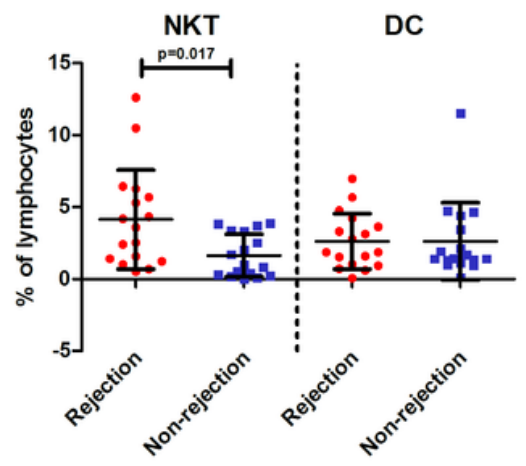

\section{Figure 6}

Percentages of lymphocyte subsets increased in patients with acute rejection. Comparison of absolute numbers (A-C) and percentages (D-F) of T, TCD4, TCD8, B, NK, NKT, and DC between liver transplant recipients with $(n=17)$ and without rejection $(n=17)$. Bars represent mean and standard deviation. $T$, CD3+T cells; TCD4, CD3+CD4+T cells; TCD8, CD3+CD8+T cells; B, CD19+B cells; NK, CD56+CD16+Natural killer cells; NKT, CD3+CD56+CD16+Natural killer T cells; DC, lin1-CD11c+ and lin1-CD123+Dendritic cells 
A

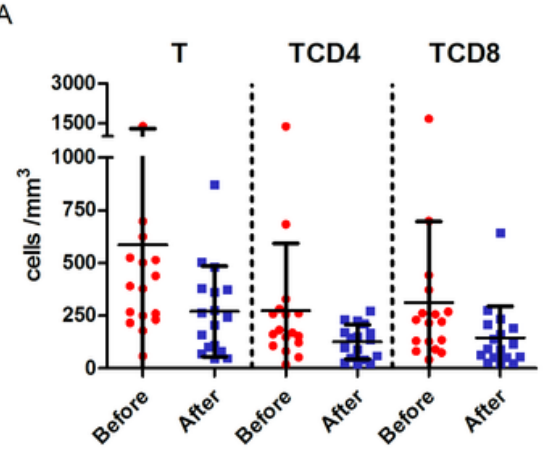

D

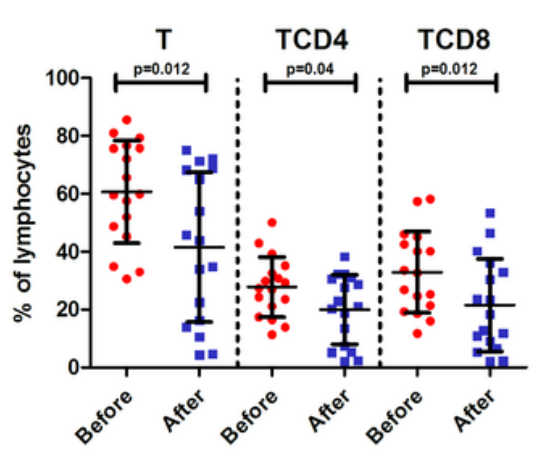

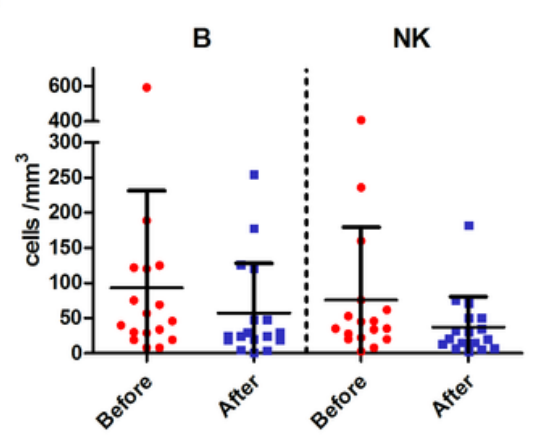

$E$

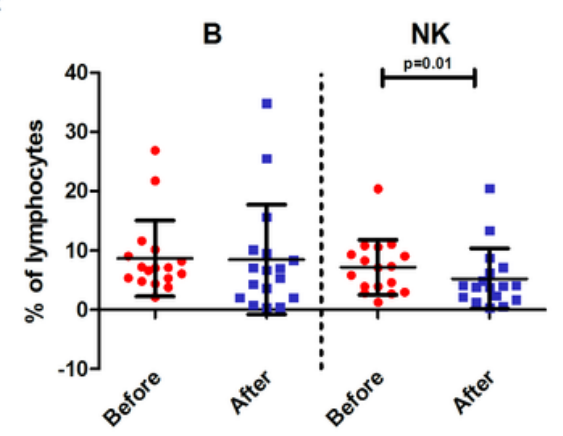

C

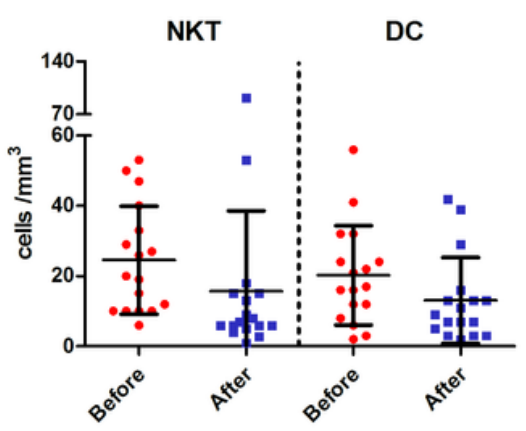

$\mathrm{F}$

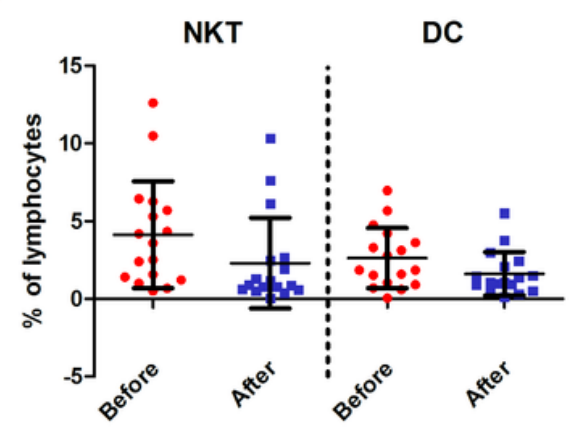

Figure 7

Percentages of lymphocyte subsets decreased after anti-rejection therapy Comparison of absolute numbers (A-C) and percentages (D-F) of T, TCD4, TCD8, B, NK, NKT, and DC before $(n=17)$ and after $(n=17)$ anti-rejection therapy. Bars represent mean and standard deviation. T, CD3+T cells; TCD4, CD3+CD4+T cells; TCD8, CD3+CD8+T cells; B, CD19+B cells; NK, CD56+CD16+Natural killer cells; NKT, CD3+CD56+CD16+Natural killer T cells; DC, lin1-CD11c+ and lin1-CD123+Dendritic cells; Before, before anti-rejection therapy; After, after anti-rejection therapy

\section{Supplementary Files}

This is a list of supplementary files associated with this preprint. Click to download.

- SupplFigure1.tif

- suppl.doc 